Slavica

bruxellensia

\section{Slavica bruxellensia}

Revue polyphonique de littérature, culture et histoire

slaves

$5 \mid 2010$

Après 1989

\title{
Emanuele Liaci, Il gatto che si mordeva la coda
}

\section{Lucia Pascale}

\section{OpenEdition \\ Journals}

Édition électronique

URL : http://journals.openedition.org/slavica/332

DOI : $10.4000 /$ slavica.332

ISSN : 2034-6395

Éditeur

Université libre de Bruxelles - ULB

\section{Édition imprimée}

Pagination : 91-92

ISSN : 2031-7654

\section{Référence électronique}

Lucia Pascale, "Emanuele Liaci, Il gatto che si mordeva la coda », Slavica bruxellensia [En ligne], 5 | 2010, mis en ligne le 09 juillet 2012, consulté le 22 septembre 2020. URL : http://journals.openedition.org/ slavica/332 ; DOI : https://doi.org/10.4000/slavica.332

Ce document a été généré automatiquement le 22 septembre 2020.

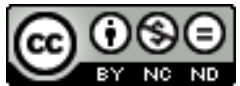

Les contenus de Slavica bruxellensia sont mis à disposition selon les termes de la Licence Creative Commons Attribution - Pas d'Utilisation Commerciale - Pas de Modification 3.0 France. 


\title{
Emanuele Liaci, Il gatto che si mordeva la coda
}

\author{
Lucia Pascale
}

RÉFÉRENCE

Emanuele Liaci, Il gatto che si mordeva la coda, Rome, Il Filo, 2007, 160 p. 
1 Il gatto che si mordeva la coda (Le Chat qui se mordait la queue) est le premier livre du poloniste et professeur Emanuele Liaci (1976). Sur un arrière-fond autobiographique, ce roman à la première personne fait interagir Ferdy Durke, Gingio pour les intimes, une figure inspirée du roman de Witold Gombrowicz, avec Mattia Pascal, un célèbre personnage de la littérature italienne né sous la plume de Luigi Pirandello. L'histoire commence à Rome, le héros-narrateur doit entamer son premier jour de travail comme interprète polonais-italien de Ferdy Durke dans un procès contre Mattia Pascal, lequel est accusé d'homicide et de faux témoignage. Mais voilà que le procès est reporté de dix jours, laps de temps qui lui donne l'opportunité de rejoindre son client, sur la demande de celui-ci, à

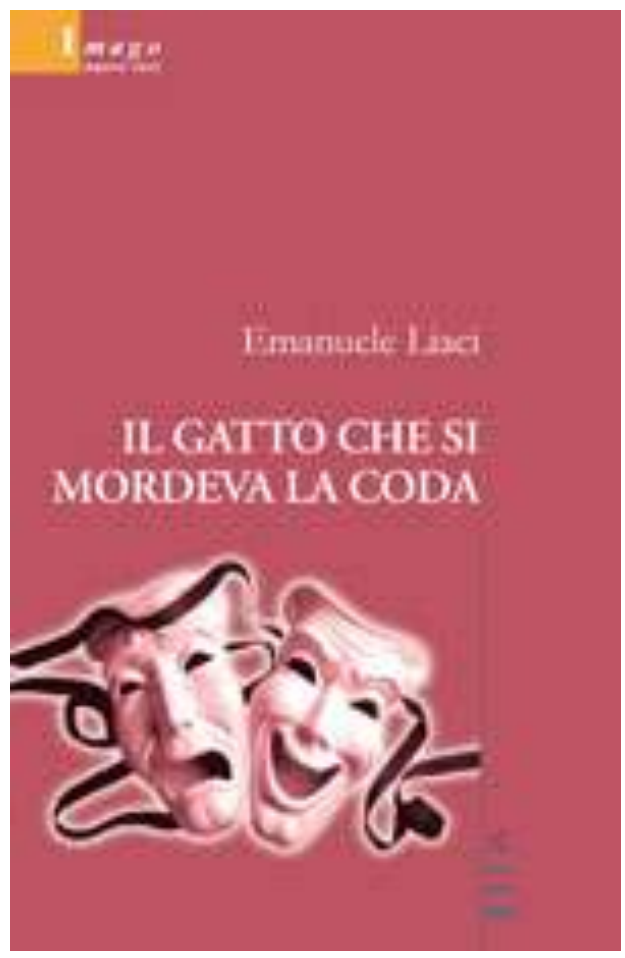
Varsovie. Il imagine alors emmener avec lui Mattia Pascal afin de le sauver en le confrontant à son adversaire. Toutefois, le protagoniste se retrouve littéralement «victime de son propre héroïsme » (p. 52) : croyant faire marcher Durke et Pascal dans son plan, il tombe dans le leur. Ces derniers ayant fomenté le projet de le démasquer, de le révéler à lui-même, de le libérer de la forme.

2 Le problème de la forme est tant le trait d'union entre les trois écrivains et le fil conducteur du récit que le sujet même du roman. Liaci a eu l'idée géniale de réunir et surtout de redonner vie aux conceptions de forme de Gombrowicz et de Pirandello. Pour ce faire, il prolonge Il fu Mattia Pascal (Feu Mathias Pascal, 1904) et Ferdydurke (1938) de telle manière à provoquer une rencontre entre Ferdy Durke et Mattia Pascal sur un pont à Rome: Durke «cuculise " Mattia Pascal, en lui suggérant le fameux meurtre dont il est accusé, qui consiste à abandonner la forme d'Adriano Meis, la deuxième identité qu'il s'était créée, et de retourner à son ancienne forme, celle de Mattia Pascal. Réunis par le narrateur de Il gatto..., les deux personnages vont ensuite l'aider à résoudre son problème de forme. Comme il l'explique dans sa préface, le héros et narrateur est en pleine crise existentielle : arrivé à l'âge de trente ans, il sent qu'il doit passer un nouveau cap pour devenir un adulte. Toutefois, face à cela, il sent un « inconfort physique » car il a peur d'emprisonner son corps dans une forme pour se conformer à une idée d'existence déjà établie. Cet « inconfort physique » devient ainsi un « inconfort social » puisqu'il craint d'être perçu par les autres tel qu'il n'est pas. Et le danger est qu'il se comporte tel que les autres le voient, provoquant par là un second « inconfort physique». Ses trente ans annoncent la perspective de cet inconfort. Par ce roman, il aspire à trouver un équilibre entre ses deux moi. Et finalement, il arrivera à se mordre la queue...

3 Ce livre n'est pas seulement original, intéressant et divertissant, il est surtout courageux. Il est audacieux de reprendre et de prolonger des œuvres de maîtres de la 
littérature mondiale. En outre, ce geste témoigne d'une ouverture interculturelle (visible par l'emploi fréquent de mots polonais) particulièrement estimable. Cela passe, d'une part, par une mise en évidence de thèmes universaux, lesquels ne peuvent qu'amener le lecteur à s'interroger sur lui-même, et, d'autre part, par des efforts de transmission de la culture et de l'histoire polonaises à son public italianophone. Liaci réussit ainsi à communiquer son univers et surtout à se faire comprendre du lecteur. Il gatto... est un roman complexe qui comprend plusieurs niveaux d'interprétation, mais l'auteur parvient à le rendre accessible par un style limpide, une langue vivante, moderne, une structure claire et un suspens bien mené. Aussi les spécialistes de la littérature trouveront-ils leur bonheur dans le labyrinthe intertextuel de citations, imitations, allusions (y aurait-t-il un retour à Sinclair Lewis ?) voire carrément de symétries avec d'autres livres (précisément avec Ferdydurke). Sans parler des notes de Roger Waters, l'ex-membre du groupe Pink Floyd, qui imprègnent toute la partition de Liaci. Pour terminer, je soulignerai la pertinence avec laquelle l'auteur représente la Varsovie d'aujourd'hui tant dans sa dimension historique que sociale, cette ville qui regarde vers l'Ouest, sans toutefois pouvoir oublier qu'elle était tout autre il y a cinquante ans, " cette ville paradoxalement vieille et pleine de cicatrices de jeunesse » (p. 137).

4 À lire très bientôt en polonais.

\section{AUTEURS}

\section{LUCIA PASCALE}

Étudiante de l'Università degli studi di Napoli "L'Orientale" 